\title{
Brenner Tumor
}

National Cancer Institute

\section{Source}

National Cancer Institute. Brenner Tumor. NCI Thesaurus. Code C39954.

A usually benign tumor composed of solid and cystic nests of epithelial cells resembling transitional epithelium; it is surrounded by an abundant stromal component that is dense and fibroblastic in nature. 